\title{
A linguagem tabu em contexto: um estudo exploratório da linguagem tabu do ponto de vista das variáveis do registro
}

\section{Taboo Language in Context: An Exploratory Study of Taboo Language from the Point of View of Register}

Catarina Xavier*

*Universidade de Lisboa (ULisboa), Centro de Estudos Anglísticos, Lisboa / Portugal catarina.andradexavier@gmail.com

https:// orcid.org/0000-0002-2687-1782

RESUMO: Os falantes interagem através dos recursos linguísticos ao seu dispor para produzir significados ao nível da compreensão do mundo que os rodeia e dos restantes falantes (EGGINS, [1994] 2004, p. 11). O falante conhece, então, um código para cada situação comunicativa e adequa as suas seleções estilísticas ao contexto em que as produz. Neste enquadramento, este artigo exploratório investiga a linguagem tabu do ponto de vista das variáveis do contexto situacional, como propostas por Halliday (1978, [1985] 2014). Segue, por um lado, uma abordagem teórica onde propõe o cruzamento das variáveis do registro com os conceitos de uso marcado e não marcado (HYMES, 1974); e, por outro, aplica esta proposta num corpus escolhido para o efeito. Os resultados, de ordem quantitativa, demonstram o predomínio do uso não marcado da linguagem tabu no corpus.

PALAVRAS-CHAVE: linguagem tabu; linguística sistémico-funcional; uso marcado e não marcado.

ABSTRACT: Language users make use of several linguistic resources to make meanings regarding the world around them as well as others (EGGINS, [1994] 2004, p. 11). The user then recognizes a specific code for each communicative situation and selectively adapts his/her options to the particular context. Against this background, this article sets out to investigate taboo language from the standpoint of Register variables, proposed by Halliday (1978; [1985] 2014). On the one hand, we follow a theoretical approach by proposing an intersection between the register variables and the concept of markedness (HYMES, 1974). On the other hand, we make use of this proposal in a purpose-built corpus. Results show the predominance of the unmarked use of taboo in the corpus. KEYWORDS: taboo language; systemic-functional linguistics; markedness. 


\section{Introdução}

Os falantes de uma língua baseiam as suas escolhas linguísticas na análise que fazem do contexto que os rodeia. Estas escolhas não são, pois, aleatórias, mas sim norteadas por determinados objetivos que acarretam valores sócio semióticos particulares. A propósito, Halliday (1978), refere:

Como é que tentamos compreender a linguagem em uso? Olhando para aquilo que o falante diz no contexto do que ele podia ter dito, mas não disse, enquanto atualização no contexto de um potencial. Consequentemente, o contexto é definido paradigmaticamente: o uso da língua significa fazer escolhas no contexto de outras escolhas (p. 52).

Assim, quando o objetivo de um estudo é analisar a linguagem em contexto, a Linguística Sistémico-Funcional (LSF) revela-se imprescindível porque é "uma teoria de descrição gramatical, uma construção teóricodescritiva coerente que fornece descrições plausíveis sobre o como e o porquê de a língua variar em função e em relação com grupos de falantes e contextos de uso" (GOUVEIA, 2009, p. 14). Esta teoria, inicialmente proposta por Michael Halliday (1973, 1975, [1985] 2014), fornece instrumentos de descrição e, consequentemente, um modelo de análise de textos (GOUVEIA, 2009, p. 14), que nos permitem analisar sistematicamente as variáveis do contexto situacional e cultural.

Apesar da sua importância no estudo da linguagem no geral, notamos uma lacuna na literatura no que diz respeito ao estudo da linguagem tabu em contexto, mais especificamente relativamente às variáveis do Registro, i.e. do contexto situacional, imediato. Tal como Bednarek (2019, p. 30) também refere, a linguagem tabu tem sido tratada pela LSF de forma inconsistente. Para além de algumas menções esparsas, e pouco precisas, encontradas em literatura de referência da LSF (BEDNAREK, 2019, p. 31), não encontrámos uma proposta de análise sistemática da linguagem tabu do ponto de vista das variáveis situacionais, relevância seja dada ao trabalho de Bednarek (2019) sobre o lugar da linguagem tabu no âmbito da LSF no que diz respeito aos significados interpessoais.

Acreditamos que o estudo da linguagem tabu enquanto fenómeno linguístico exige um olhar detalhado sobre o seu uso em contexto que permita não só descrever as variáveis situacionais enquanto modeladoras das escolhas dos falantes, mas também perceber o seu grau de adequação ao 
contexto. Assim, este trabalho tem como objetivo estudar a linguagem tabu em contexto, recuperando a proposta da Linguística Sistémico-Funcional, porque estuda a forma como os falantes usam a linguagem consoante $o$ contexto, e enquanto sistema semiótico (EGGINS, [1994] 2004), cruzando-a com os conceitos de uso marcado e de uso não marcado de Hymes (1974), autor que desde cedo discute a adequação da linguagem ao contexto, para compreender a adequação do uso da linguagem tabu.

Facilmente reconhecemos situações em que o recurso a palavras tabu é inadequado, tendo em conta o nosso interlocutor, o tipo de linguagem utilizado para a atividade que nos ocupa ou o modo do texto que utilizamos. Considerando isto, recuperamos Halliday (1978, [1985] 2014) que propõe como três dimensões do registro: 1) o campo, 2) as relações, e 3) o modo, que correspondem respectivamente ao foco da atividade e ao assunto da produção textual; às relações de poder e de solidariedade entre os falantes e à estrutura de papéis articulada entre eles; e ao papel da linguagem e ao canal de produção do texto (HALLIDAY, [1985] 2014; EGGINS, [1994] 2004; GOUVEIA, 2009, entre outros), para as cruzar com a proposta de Hymes (1974).

Após esta introdução, damos início a este artigo com uma apresentação da linguagem tabu, que julgamos necessária pela inconsistência terminológica relacionada com o conceito. Aqui o definimos e apresentamos a sua génese para, em seguida, brevemente expor as suas motivações. $\mathrm{O}$ artigo discute depois a proposta de cruzamento das variáveis do registro com o uso marcado e não marcado da linguagem tabu, para a aplicar posteriormente na análise de um corpus escolhido para dar resposta ao objetivo aqui apresentado. Após a exposição dos resultados deste estudo exploratório, concluímos com as suas limitações e direções de investigação futura.

Acreditamos na pertinência desta proposta, teoricamente, no que diz respeito não só à análise da linguagem tabu do ponto de vista das variáveis do registro, mas também ao seu uso marcado e não marcado. Para além disto, esperamos poder estimular a discussão acadêmica relativamente a exceções a esta proposta bem como à aplicabilidade desta proposta noutros corpora de linguagem ficcional ou natural.

\section{A linguagem tabu}

A linguagem tabu tem sido tema de estudo frequente no âmbito acadêmico (MONTAGU, 1967; ANDERSSON, TRUDGILL, 1990; 
LANCKER, CUMMINGS, 1999; JAY, 2000; KARJALAINEN, 2002; ALLAN, BURRIDGE, 2006, 2009; JOSEPH, 2006; MCENERY, 2006; CRESSMAN et al., 2009; STAPLETON, 2010; LJUNG, 2011; BEERS FÄGERSTEN, 2012; BEERS FÄGERSTEN, STAPLETON, 2017; BEDNAREK 2019, entre outros). Contudo, é de relevar a inconsistência terminológica correlacionada com a linguagem tabu, referida já por outros autores (BEERS FÄGERSTEN, 2012; GODDARD, 2015; BEDNAREK, 2019, entre outros). Mesmo no âmbito da Linguística, a confusão de termos é clara tanto em português: linguagem tabu, palavrões, expletivos, linguagem ofensiva, insultos, calão, entre outros; como em inglês: swear words, offensive language, slurs, insults, curse words, bad language, profanity, expletives, taboo words (BEERS FÄGERSTEN, 2012; GODDARD, 2015; BEDNAREK, 2019).

Neste enquadramento, importa então definir e apresentar a linguagem tabu enquanto tópico deste trabalho para só então a analisar no âmbito das variáveis do Registro.

\subsection{Definição e gênese}

O conceito de linguagem tabu deve ser categoricamente correlacionado com palavras ou expressões proibidas, léxico relacionado com temas específicos do imaginário tabu - como os órgãos e atos relativos ao sexo e à escatologia; o corpo e eflúvio corporal; as doenças e a morte; a nomeação de seres, objetos e locais sagrados; e a alimentação e sua preparação (ALLAN, BURRIDGE, 2006, p. 1).

Ainda assim, do ponto de vista linguístico, nada distingue estas de outras palavras (AKMAJIAN et al., 2001; KARJALAINEN, 2002; ALLAN, BURRIDGE, 2006; MCENERY, 2006). McEnery (2006, p. 1), por exemplo, refere: "merda e todas as outras palavras que classificamos como 'má linguagem' são inócuas na medida em que nada as distingue particularmente enquanto palavras". Akmajian et al. (2001, p. 307) sublinham, no mesmo sentido: "O que é considerado linguagem tabu é algo definido pela cultura, e não algo inerente à linguagem”. Desta forma, fica claro que o estatuto destas palavras assenta apenas nas atitudes da comunidade linguística.

As palavras tabu alteram o seu estatuto por um processo social pelo qual uma classe dominante censura palavras tabu, de acordo com os seus próprios temas tabu. Ao longo dos tempos, as palavras tabu passam a ser reconhecidas pela comunidade como palavras proibidas ou inadequadas na 
maioria dos contextos, e mantidas pela convenção social. Resultam daquilo que Milroy e Milroy ([1985] 2012) referiam como ideologia da padronização, i.e. o conjunto de convicções legitimadas pela generalidade da comunidade que geram atitudes desfavoráveis a este tipo de expressões. Allan e Burridge (2006) e McEnery (2006) referem ainda que este processo social se alicerça nos valores, ideias e convicções da classe média sobre o limite dos bons costumes.

\subsection{Motivações da linguagem tabu}

Ainda que a linguagem tabu esteja associada a um contexto de proibição, esta mantém-se no discurso dos falantes.

Assim, importa brevemente referir as motivações que levam à opção por este recurso linguístico em determinados contextos, com o objetivo de, em secção seguinte, contextualizar e descrever o seu uso no âmbito das variáveis do Registro.

\subsubsection{Motivações neurolinguísticas}

Estudos diversos têm vindo a correlacionar a linguagem tabu com o campo das emoções do ser humano, mostrando que o uso de palavras tabu pode resultar de um processo neurológico involuntário (JAY, 2000; ALLAN, BURRIDGE, 2006). O facto de grande parte dos seres humanos proferirem expressões tabu em resposta à dor, de forma involuntária é, portanto, um dado sintomático. Anthes (2010), refere:

Dizer palavrões pode aumentar a tolerância à dor dos participantes. Foi pedido aos participantes que submergissem as mãos numa banheira de água gelada e que as mantivessem lá o máximo que conseguissem. Quando lhes era permitido dizer palavrões, os participantes eram capazes de aguentar mais tempo as mãos na água gelada (p. 22).

Jackson (1874) é o primeiro a referir que este tipo de linguagem tem uma regência cerebral diferente da linguagem comum.

Depois desta investigação, várias pistas científicas que apontam para a diferente lateralização cerebral da linguagem tabu têm sido referidas. Por exemplo, Lancker e Cummings (1999, p. 84) estudam as causas do recurso excessivo a elementos tabu por parte de doentes com lesões cerebrais 
traumáticas extensas, chegando à conclusão de que este tipo de linguagem está potencialmente relacionado com o hemisfério direito, em oposição à linguagem comum, associada ao lado esquerdo do cérebro, no seguimento dos estudos iniciais de Broca (1865).

Os autores concluem:

As diferenças entre expletivos e palavras e expressões compostas, identificadas com as conhecidas diferenças no processamento no hemisfério esquerdo e direito, levavam à consideração do hemisfério direito como candidato mais provável na modulação da produção motora dos expletivos. Esta assunção teórica é fundamentada pela observação de palavras tabu intactas na afasia severa (após danos extensos no hemisfério esquerdo) e em pacientes adultos hemisferectomizados (LANCKER, CUMMINGS, 1999, p. 96).

Allan e Burridge (2006, p. 246-247) apontam estudos vários onde se expõem casos de doentes com Síndrome de Tourette ou com Alzheimer que, para além de não controlarem o uso comum da linguagem, aumentam o recurso a elementos tabu. Este sintoma, geralmente reconhecido como coprolalia, uma necessidade involuntária de proferir palavras consideradas tabu em determinado contexto, é incontrolável e por vezes angustiante para o paciente, que se vê incapaz de suspender estes impulsos.

Adicionalmente, alguns estudos têm também confirmado a existência de reações involuntárias à linguagem tabu, tais como o aumento do ritmo cardíaco, a leitura mais lenta de palavras tabu ou o surgimento de arrepios (ALLAN, BURRIDGE, 2006, p. 244-246), o que leva à conclusão dos autores: "Os resultados são sempre os mesmos: as palavras tabu são mais estimulantes do que as palavras não tabu e nós, aparentemente, guardamolas de forma diferente na nossa memória” (ALLAN, BURRIDGE, 2006, p. 244).

\subsubsection{Motivações psicológicas}

A par das causas neurológicas que se crê existirem, a bibliografia relacionada aponta também para motivos de ordem psicológica no uso de palavras tabu. Allan e Burridge (2006, p. 252) reconhecem: "Há um ganho psicológico em libertar a pressão e expressar emoção extrema através de um desenrolar de expletivos e palavras proibidas". 
De facto, a reação a fatores exteriores de irritação que implicam frustração ou raiva (JAY, 2000, p. 55) passa frequentemente pela exteriorização através da linguagem tabu. O "ganho psicológico" de que falam os autores pode assim advir de diversas razões: alívio da frustração, reação à emoção muito forte, recuperação de estabilidade psicológica ou fuga ao stress (MONTAGU, 1967; ANDERSSON, TRUDGILL, 1990; ALLAN, BURRIDGE, 2006; SOLER PRADO, 2011). Allan e Burridge (2006, p. 252) apontam ainda para um aspecto psicológico mais profundo, revelado pela necessidade do ser humano em quebrar tabus e contrariar as convenções sociais: "Existe a emoção da transgressão: é libertador desafiar a proibição por meio da violação dos tabus linguísticos".

\subsubsection{Motivações sociais}

Ryan (1979, p. 149) afirma que as opções linguísticas não padrão podem preencher dois tipos de objetivos. Por um lado, podem exprimir solidariedade entre membros de um grupo e, por outro lado, provocar distanciamento entre pessoas ou grupos sociais.

Este enquadramento é particularmente útil quando cruzado com o conceito de prestígio, como integrado pela Sociolinguística. A este conceito associamos a noção de valor social que determinadas opções linguísticas assumem na comunidade, em oposição ao estigma que outras opções da língua comportam. Labov $(1966,1972,2001)$ expande o conceito ao defender dois tipos de prestígio e de normas linguísticas. O autor reconhece a existência de um prestígio explícito, próprio das opções padronizadas da língua e dos seus falantes; mas propõe, por outro lado, o conceito de prestígio encoberto, que corresponde à valorização de opções linguísticas não padronizadas a que os falantes recorrem em esferas sociais específicas, como forma de gerar solidariedade e proximidade com um receptor ou com membros de um grupo.

Labov (2001, p. 191) assim sugere: "é fundamental considerar uma estrutura de crença encoberta: que os falantes sentem que a adopção da forma linguística levará os outros a atribuírem-lhes traços positivos do grupo, permitindo-lhes partilhar os privilégios desse grupo". Paradoxalmente, o uso da linguagem tabu pode ser simultaneamente estigmatizado, por um lado, e valorizado, por outro. O falante que usa o tabu pode, consequentemente, esperar que lhe seja atribuído prestígio relativo porque utiliza uma marca 
lexical valorizada positivamente pelo grupo ou pelo interlocutor. Aliás, a manutenção da linguagem tabu ao longo do tempo, apesar do contexto de atitudes explicitamente desfavorável, parece ficar justificada também pela proposta de prestígio encoberto de Labov (1966, 1972, 2001). Labov (2001), resume:

Para explicar o facto de as formas discursivas estigmatizadas pelas classes sociais dominantes se manterem por longos períodos, e até de se expandirem perante tal estigmatização, somos forçados a considerar a existência de um conjunto de valores oposto que não emerge imediatamente em situações formais (LABOV 1972, p. 313), e alguma evidência sólida foi já produzida no sentido deste prestígio encoberto (p. 23-24).

Podemos, então, concluir que também o uso de linguagem tabu poderá significar que o falante opta por palavras reconhecíveis e valorizadas pelos restantes membros do grupo, que tipicamente usam estas palavras. Não obstante estar afastada do cânone padronizado da língua, a linguagem tabu pode, assim, ser valorizada pelo seu prestígio encoberto em determinadas situações, por grupos específicos, que a utilizam para criar solidariedade. Esta é, aliás, a maior referência para o recurso a linguagem tabu de acordo com Joseph (2006):

A maior parte das palavras tabu (...) não aparenta preencher qualquer das funções agora descritas [revolta, proibição, ofensividade, inconveniência] mas, ao invés, assume uma função mais positiva de unir as pessoas através da sua mútua revogação do tabu (p. 86).

Ainda assim, a linguagem tabu pode, também, preencher o propósito comunicativo de afastamento entre indivíduos ou elementos de um grupo porque gera distância relativamente à outra pessoa ou ao grupo que rejeita este tipo de linguagem. O uso deste fenómeno linguístico é frequentemente relacionado com o objetivo do falante de se posicionar contra o interlocutor, chocando-o pelas suas opções linguísticas. Por pressões do padrão, símbolo do prestígio linguístico e social, o falante poderá querer insurgir-se contra o poder e estabelecer uma marca identitária do seu idioleto, socioleto ou como forma de intensificar a situação comunicativa, por motivos de ordem vária. Para além disto, o uso da linguagem tabu por parte de um falante pode ser 
considerado como inadequado ao contexto por outro falante ou por um grupo, gerando um contexto de atitudes e de valores negativo relativamente ao falante, que vê diminuído o seu estatuto relativo, por ter utilizado opções linguísticas consideradas inadequadas (ALLAN, BURRIDGE, 2006, p. 122).

\section{O uso da linguagem tabu em contexto: as variáveis do Registro e o uso (não) marcado}

\subsection{Do uso marcado e não marcado}

No âmbito específico da Sociolinguística, Dell Hymes (1974) introduziu o conceito de competência comunicativa, aplicável, principalmente, ao estudo da forma como os falantes utilizam determinadas opções linguísticas em detrimento de outras, em resultado da análise, e do efeito, das normas sociais que afetam as relações humanas. Assim, interessanos o enquadramento da adequação da linguagem ao contexto, que Hymes caracteriza, importando conceitos da Escola de Praga, que lhe permite distinguir usos marcados e não marcados. No primeiro caso, as opções do falante surpreendem pela inadequação às variáveis contextuais e às expectativas dos falantes relativamente às formas linguísticas consideradas adequadas; no segundo caso, a linguagem utilizada pelo falante é expectável. No mesmo sentido, Oliveira (2006) importa estes conceitos e sugere os termos "linguagem surpreendente", quando as opções linguísticas de um falante entram em conflito com as normas linguísticas que ditam a adequação ao contexto discursivo; e "linguagem antecipada", quando as opções do falante correspondem às expectativas sociais tendo em conta o estatuto relativo dos falantes e outras variáveis da situação comunicativa.

Neste contexto, é adequado ponderar que também o uso de linguagem tabu é afetado pela avaliação, por parte do falante, do grau de formalidade da situação comunicativa que, entre outros fatores, decorre também do estatuto relativo dos falantes. Considerando isto, entendemos ser necessário descrever a forma como as dimensões do contexto situacional que envolve o evento linguístico tem impacto na maneira como a linguagem tabu é usada pelo falante e, a par disto, considerar as noções de adequação ou não adequação destas palavras e expressões ao dito contexto, para compreendermos o uso marcado e não marcado da linguagem tabu. 


\subsection{Das variáveis do Registro}

No âmbito da Linguística Sistémico-Funcional, a Teoria do Registro interroga-se sobre a identificação das dimensões do contexto situacional que afetam as opções dos textos que produzimos. Alicerçado nos trabalhos de Malinowski (1935) e de Firth (1951), Halliday (1978, [1985] 2014) sugere que existem três aspetos do contexto que afetam a forma como usamos a linguagem, i.e. as variáveis do registro: 1) o campo, 2) as relações, e 3) o modo, que correspondem respectivamente ao a) foco da atividade e ao assunto da produção textual; b) às relações de poder e de solidariedade entre os falantes e à estrutura de papéis articulada entre eles; e c) ao papel da linguagem e ao canal de produção do texto (HALLIDAY, MCINTOSH E STREVENS, 1964; HALLIDAY, [1985] 2014; HALLIDAY, HASAN, [1985] 1989; EGGINS, [1994] 2004; GOUVEIA, 2009, entre outros), ligadas, por sua vez, às três metafunções da linguagem (ideacional, interpessoal e textual).

Considerando isto, procedemos a uma apresentação das três variáveis num cruzamento com as noções de uso marcado e não marcado, antes de avançarmos para a aplicação da proposta num corpus.

\subsubsection{Modo}

O modo é a manifestação do código no uso da linguagem e diz respeito ao papel da linguagem na situação comunicativa. Halliday ([1985] 2014) refere:

O modo [refere-se a] que papel está a ser desempenhado pela língua e outros sistemas semióticos na situação: (i) a divisão do trabalho entre atividades semióticas e sociais (...); (ii) a divisão do trabalho entre atividades linguísticas e outras atividade semióticas, (iii) modo retórico: a orientação do texto na direção do campo (...) ou relações (...); (iv) interação: dialógica ou monológica; (v) meio: escrito ou falado; (vi) canal: fónico ou gráfico (p. 33).

Martin (1984) e, mais tarde, Eggins ([1994] 2004) sugerem que este papel envolve dois contínuos que descrevem dois níveis de distância entre a linguagem e a situação: a interpessoal e a experiencial, que, combinadas, caracterizam o contraste em situações de uso da linguagem escritas e orais (EGGINS [1994] 2004, p. 92). 
Porque os falantes fazem uso de diferentes opções linguísticas caso estejam nestas situações de uso oral ou escrito, interessa-nos especialmente a descrição de uma e de outra para a análise do tabu. A propósito, Eggins ([1994] 2004, p. 93) refere que o discurso oral é espontâneo, pautado por hesitações e repetições, léxico comum, gramática complexa e não padronizada, e vocabulário calão. Por sua vez, o discurso escrito tem, tendencialmente, um vocabulário prestigiado e denso. A autora resume, desta forma, as implicações linguísticas típicas da variável do modo em contexto linguístico oral ou escrito:

QUADRO 1 - Características prototípicas da linguagem oral e escrita

\begin{tabular}{|c|c|}
\hline Linguagem Oral & Linguagem Escrita \\
\hline Organização dialógica & Organização em monólogo \\
\hline Dependente do contexto & Independente do contexto \\
\hline Estrutura dinâmica & Estrutura sinóptica \\
\hline Fenómenos de espontaneidade & Redação definitiva \\
\hline Léxico comum & Léxico prestigiado \\
\hline Gramática não padrão & Gramática padrão \\
\hline Estrutura gramatical complexa & Estruturas gramaticais simples \\
\hline Lexicalmente esparsa & Lexicalmente densa \\
\hline
\end{tabular}

Fonte: Baseado em Eggins ([1994] 2004, p. 93).

Estas tendências podem ter efeitos no uso de linguagem tabu já que é mais comum em situações informais, e, maioritariamente, em contextos orais (EGGINS, [1994] 2004, p. 101). Autores como Collins e Hollo (2000) confirmam que a linguagem tabu é, de facto, um dos indicadores linguísticos do discurso oral informal. Por sua vez, McEnery e Xiao (2004, p. 236), em análise do British National Corpus, referem que a palavra "fuck" é doze vezes mais frequente no discurso oral do que no discurso escrito, a par da palavra "fucking", vinte vezes mais comum no uso oral. Os autores sugerem que estes totais se devem não só à informalidade geralmente característica do discurso oral, mas também ao processo de autocensura que normalmente afeta o discurso escrito. 
No entanto, as características do discurso oral e do discurso escrito, bem como as expectativas dos falantes associadas a um e a outro, têm vindo a ser modificadas pelo uso das novas tecnologias. As redes sociais e o envio de mensagens escritas em smartphones fazem uso de um tipo de escrita tendencialmente informal, próximo da linguagem oral, principalmente entre falantes com envolvimento afetivo elevado e idades próximas. Este recente contexto de escrita informal, caracterizado por um cuidado reduzido com a correção linguística e por uma grande influência da oralidade, vem alterar a rigidez das propostas iniciais de descrição linguística da oralidade e da escrita. Por isso, e com base na descrição de corpora, Tagg (2009) propõe que as mensagens escritas constituem uma nova variedade com características específicas. Neste enquadramento, acreditamos que a nova informalidade da escrita pode influenciar o uso da linguagem tabu nestes contextos, tornando menos chocante o seu uso em mensagens escritas em celulares ou redes sociais, desde que a relação entre os participantes seja próxima. Para além disto, deve considerar-se ainda a existência de contextos orais espontâneos e formais, tais como situações de contato infrequente entre falantes cujo envolvimento afetivo é fraco ou cujos poder e prestígio são díspares. Exemplos destas situações seriam um contexto de consulta médica ou um contexto de troca de impressões entre participantes de uma conferência, em que o recurso a palavras tabu seria visto como inadequado ao contexto.

Assim, podemos deduzir que a linguagem tabu se associa tendencialmente a contextos orais de uso da linguagem porque não se identifica com o léxico prestigiado que tipicamente se associa à escrita e à fala em contextos formais. Para além disso, pode estar associada a contextos de escrita informal em que os falantes tenham relações próximas. $\mathrm{O}$ uso da linguagem tabu seria, então, prototipicamente considerado marcado ou surpreendente, de acordo com as definições de Hymes (1974) e Oliveira (2006), em contextos discursivos escritos ou de fala formais, e não marcado ou antecipado, em contextos discursivos informais. O quadro que se segue assim o resume: 
QUADRO 2 - Proposta de cruzamento da variável do modo com a adequação da linguagem tabu ao contexto

\begin{tabular}{|c|c|c|c|}
\hline \multicolumn{2}{|c|}{ Fala } & \multicolumn{2}{c|}{ Escrita } \\
\hline Informal & Formal & Formal & Informal \\
\hline Uso não marcado & Uso marcado & Uso marcado & Uso não marcado \\
\hline
\end{tabular}

\subsubsection{Relações}

A variável das relações é relativa aos falantes e ao tipo de relação estabelecida entre eles num evento linguístico, evoluindo, entre outros aspectos, num continuum gradativo de formalidade entre eles. Halliday ([1985] 2014, p. 33) apresenta a seguinte definição para esta dimensão do uso da linguagem:

As relações [referem-se a] quem está envolvido na situação:

(i) aos papéis desempenhados por aqueles que participam na atividade sócio semiótica (...); e (ii) os valores que os participantes incutem no domínio (quer neutros quer carregados, positivamente ou negativamente).

Naturalmente, entendemos que a forma como usamos diferentes opções linguísticas depende também do interlocutor e dos papéis sociais dos falantes na situação comunicativa (EGGINS, [1994] 2004, p. 99). Íntimas, coloquiais, informais ou formais, as relações entre falantes afetam as suas escolhas discursivas, dependendo das diferenças de poder entre falante e interlocutor.

A propósito disto, Eggins ([1994] 2004, p. 99-100) questiona as variáveis que influenciam a variação na língua com base nos papéis sociais dos falantes. Para isso, recupera a proposta de Poynton (1985), que recuperamos para dar resposta às necessidades de análise das relações entre falantes e suas consequências no uso de linguagem tabu. A autora sugere que 1) o poder; 2) a frequência do contato; e 3) o envolvimento afetivo são os aspectos dos papéis sociais que têm impacto na forma como utilizamos umas e outras opções linguísticas.

A primeira variável, o poder, corresponde às diferenças entre os papéis sociais e diverge numa escala que evolui do poder igual ao poder desigual, em que um dos falantes tem maior poder do que o outro. De acordo com isto, propomos que nos contextos discursivos em que o poder entre 
falantes é igual ou semelhante e o objetivo comunicativo é o estabelecimento de relações de solidariedade ou de intimidade, o uso da linguagem tabu não é surpreendente; por outro lado, nos casos em que os falantes têm poder desigual e os objetivos da mensagem são o estabelecimento de distância para com o interlocutor ou a criação de conflito, então, concluímos que a linguagem tabu tem um uso marcado na situação comunicativa.

No que ao contato diz respeito, Poynton (1985) afirma que os nossos papéis sociais e, consequentemente, o nosso uso da língua, se distinguem também pela frequência de contato entre os falantes da situação comunicativa, que varia num continuum do contato frequente até ao contato ocasional. No seguimento desta proposta, notamos ser mais expectável o uso de linguagem tabu entre falantes cujo contato é frequente e, daí, considerarmos este uso como não marcado. Por outro lado, o recurso a palavras tabu é menos expectável quando os eventos linguísticos entre falantes são escassos e, por isso, identificamo-lo como uso marcado.

O envolvimento afetivo diz respeito ao empenhamento emocional entre os falantes da situação comunicativa e varia num continuum que se estende desde o envolvimento elevado ao envolvimento baixo. De acordo com esta proposta, o recurso linguístico tabu é considerado como mais adequado em contextos em que o envolvimento afetivo é elevado, em oposição a situações comunicativas em que este comprometimento é baixo. Identificamos, consequentemente, estas situações comunicativas como uso não marcado e uso marcado, respectivamente.

Estabelece-se, pois, uma relação entre as variáveis vinculadas com as relações entre falantes e o contexto (EGGINS, [1994] 2004, p. 100), que refletem também circunstâncias de situações comunicativas formais ou informais:

QUADRO 3 - Proposta de cruzamento da variável das relações com a adequação da linguagem tabu ao contexto

\begin{tabular}{|c|c|}
\hline Informal & Formal \\
\hline Poder igual & Poder desigual, hierárquico \\
\hline Contato frequente & Contato não frequente \\
\hline Envolvimento afetivo elevado & Envolvimento afetivo fraco \\
\hline Uso não marcado & Uso marcado \\
\hline
\end{tabular}


Não obstante estes serem os cruzamentos dominantes e expectáveis entre as variáveis do poder, do contato e do envolvimento afetivo, e o uso da linguagem tabu, há algumas exceções a considerar, que podem alterar a adequação destas palavras ao contexto. Este é o caso, por exemplo, de situações de contato não frequente, envolvimento afetivo nulo e poder irrelevante, como insultos entre duas pessoas no trânsito; ou de situações de contato frequente e envolvimento afetivo relativo, em que a linguagem tabu não seria considerada como inadequada ao contexto, mas o poder desigual dos falantes gera a inadequação do uso da linguagem tabu, como numa situação discursiva entre um funcionário e o seu chefe. Apesar da ponderação e da pertinência das exceções, a necessidade de analisar a linguagem tabu em contexto orienta a simplificação da proposta acima exposta. Nestes termos, consideramos que a adequação das palavras tabu ao contexto está tendencialmente relacionada com situações comunicativas em que os falantes têm poder igual, contato frequente e envolvimento afetivo elevado; e, por outro lado, a sua inadequação ocorre em contextos em que os falantes têm poder diferente, contatam ocasionalmente e têm baixo envolvimento emocional. Definimos, portanto, que a primeira corresponde a um uso não marcado da linguagem tabu e que a segunda corresponde a um uso marcado.

\subsubsection{Campo}

Esta variável do uso da linguagem em contexto diz respeito à "codificação da experiência, àquilo de que se fala, ao assunto do texto" (GOUVEIA, 2009, p. 27). Nas palavras de Halliday ([1985] 2014, p. 33): "Campo [refere-se ao] que está a acontecer na situação: (i) a natureza das atividade social e semiótica; e (ii) o domínio de experiência com que esta atividade se relaciona (o 'assunto' ou 'tópico')".

Eggins ([1994] 2004, p. 107) refere ainda que o campo varia num continuum que evolui da linguagem do dia a dia à linguagem técnica e especializada. Para a autora ([1994] 2004, p. 107-109), a variação no campo dos textos tem implicações linguísticas na medida em que, no uso de linguagem técnica ou especializada, o falante recorre ao jargão característico do tema sobre o qual fala ou escreve havendo geralmente uma pressuposição do conhecimento prévio, por parte do receptor, deste jargão e das taxonomias usadas. Por outro lado, na linguagem do dia a dia, o falante 
utiliza léxico comum, ou seja, palavras que o receptor facilmente reconhece, e estruturas gramaticais pouco complexas.

Considerando esta proposta, é adequado correlacionar o uso da linguagem tabu com a linguagem do dia a dia, e, consequentemente, identificá-lo como uso não marcado da linguagem tabu no que ao campo diz respeito, em oposição ao contexto da linguagem técnica e especializada onde o recurso à linguagem tabu seria inadequado e, portanto, o seu uso marcado. Assim:

QUADRO 4 - Proposta de cruzamento da variável do campo com a adequação da linguagem tabu ao contexto

\begin{tabular}{|c|c|}
\hline Linguagem do dia a dia & Linguagem técnica e especializada \\
\hline Termos do dia a dia & Termos técnicos \\
\hline Sintaxe simples & Sintaxe complexa \\
\hline Conhecimento comum & Pressuposições de conhecimento prévio do tema \\
\hline Uso não marcado & Uso marcado \\
\hline
\end{tabular}

\subsection{Para uma proposta da adequação da linguagem tabu ao contexto}

Considerando o anterior, sugerimos que a adequação da linguagem tabu se circunscreve, a um contexto específico caracterizado por fatores vários: a informalidade, a oralidade, a relação próxima entre os participantes da situação comunicativa e a linguagem comum a que tendencialmente recorremos em situações do dia a dia. Por outro lado, o uso marcado da linguagem tabu é identificado pela formalidade da situação comunicativa, em modo escrito e formal, pela relação distante entre os falantes, e pela linguagem técnica ou especializada de situações específicas. Não obstante considerarmos as exceções atrás referidas, propomos o seguinte: 
QUADRO 5 - Proposta de cruzamento das variáveis do Registro com a adequação da linguagem tabu ao contexto

\begin{tabular}{|l|c|c|}
\hline & $\begin{array}{c}\text { Uso marcado } \\
\text { da linguagem tabu }\end{array}$ & $\begin{array}{c}\text { Uso não marcado } \\
\text { da linguagem tabu }\end{array}$ \\
\hline Modo & $\begin{array}{c}\text { Escrito formal } \\
\text { Oral formal }\end{array}$ & $\begin{array}{c}\text { Escrito informal } \\
\text { Oral informal }\end{array}$ \\
\hline Relações & Distante & Íntima \\
\hline Campo & $\begin{array}{c}\text { Linguagem técnica } \\
\text { Linguagem especializada }\end{array}$ & Linguagem do dia a dia \\
\hline
\end{tabular}

\section{Análise}

\subsection{Descrição do corpus}

Este estudo aplica a proposta anterior num corpus de ficção audiovisual em língua inglesa, com a finalidade de identificar os usos marcados e não marcados da linguagem tabu. Os filmes escolhidos foram selecionados de acordo com o critério da qualidade, ou seja, o objetivo deste estudo é o principal orientador da escolha. Assim, o elevado número de palavras tabu foi o critério de seleção primário. A escolha foi feita com base num cruzamento de dados através da verificação de títulos de filmes nas plataformas: 1. "List of films that most frequently use the word "fuck"; 2) "Hollywood's most profane movies"; 3) IMDB-Internet Movie Database; pesquisa de filmes classificados como "restricted" de acordo com The Classification and Rating Administration.

Chegamos ao seguinte conjunto de textos:

QUADRO 6 - Textos incluídos no corpus

\begin{tabular}{|c|c|c|c|c|c|}
\hline Título & $\begin{array}{c}\text { Ano de } \\
\text { Produção }\end{array}$ & Género(s) & $\begin{array}{c}\text { Classificação } \\
\text { etária }\end{array}$ & Realizador & País \\
\hline Goodfellas & 1990 & Drama & $\mathrm{R}$ (restricted) & $\begin{array}{c}\text { Martin } \\
\text { Scorcese }\end{array}$ & EUA \\
\hline $\begin{array}{c}\text { Pulp } \\
\text { Fiction }\end{array}$ & 1994 & $\begin{array}{c}\text { Crime, Drama, } \\
\text { Thriller, }\end{array}$ & $\mathrm{R}$ (restricted) & $\begin{array}{c}\text { Quentin } \\
\text { Tarantino }\end{array}$ & EUA \\
\hline $\begin{array}{c}\text { Another } \\
\text { Day in } \\
\text { Paradise }\end{array}$ & 1998 & $\begin{array}{c}\text { Crime, Drama, } \\
\text { Thriller }\end{array}$ & $\mathrm{R}$ (restricted) & Larry Clark & EUA \\
\hline
\end{tabular}




\begin{tabular}{|c|c|c|c|c|c|}
\hline Jarhead & 2005 & Drama & $\mathrm{R}$ (restricted) & Sam Mendes & EUA \\
\hline $\begin{array}{c}\text { The } \\
\text { Departed }\end{array}$ & 2006 & $\begin{array}{c}\text { Crime, Drama, } \\
\text { Thriller }\end{array}$ & $\mathrm{R}$ (restricted) & $\begin{array}{c}\text { Martin } \\
\text { Scorsese }\end{array}$ & EUA \\
\hline $\begin{array}{c}\text { American } \\
\text { Pie: Beta } \\
\text { House }\end{array}$ & 2007 & Comédia & $\mathrm{R}$ (restricted) & Andrew Waller & $\begin{array}{c}\text { Canadá/ } \\
\text { EUA }\end{array}$ \\
\hline
\end{tabular}

Para facilitar o tratamento de dados, procurou-se online a transcrição do discurso oral dos filmes referidos. Uma vez que estes ficheiros nunca incluem uma transcrição total, foram acrescentadas as palavras em falta, com maior atenção nas cenas que incluem produção de linguagem tabu. $\mathrm{Na}$ sequência deste processo e no que diz respeito ao número de palavras, este corpus ficou, então, composto por 74491 palavras, analisáveis e tratadas no programa Word.

\subsection{Metodologia}

\subsubsection{Identificação e classificação das palavras tabu}

Para identificar as palavras tabu deste corpus, procurámos ferramentas que permitissem a categorização e classificação linguísticas da linguagem tabu em inglês. Assim, para evitar enviesamento de dados, as palavras tabu encontradas nos filmes foram verificadas individualmente em três dicionários distintos: 1) Cambridge Advanced Learner's Dictionary (CALD); 2) Collins Cobuild Dictionary for Advanced Learners (CCDAL); e 3) Oxford Advanced Learner's Dictionary (OALD).

A verificação em três dicionários distintos revelou a diversidade de critérios e de classificações destes dicionários:

QUADRO 7 - Listagem comparativa de categorias não padrão apresentadas pelos três dicionários da língua inglesa

\begin{tabular}{|c|c|c|}
\hline OALD & CALD & CCDAL \\
\hline Informal & Offensive & Vulgar \\
\hline Vulgar Slang & & Rude \\
\hline Offensive & & Offensive \\
\hline Taboo & & Slang \\
\hline & & Taboo \\
\hline
\end{tabular}


Porque a categoria única "offensive" não dá resposta às necessidades de classificação deste estudo, consideramos somente as classificações dos dicionários Collins Cobuild Dictionary for Advanced Learners (CCDAL) e Oxford Advanced Learner's Dictionary (OALD) que contemplam a classificação "tabu". Adicionalmente, nos casos em que a unidade linguística identificada não seja contemplada em qualquer destes dicionários, consultou-se o Urban Dictionary Online (UDO).

Com base na consulta destas fontes, identificámos 2069 palavras tabu nos filmes.

\subsubsection{Classificação como uso marcado ou uso não marcado das palavras tabu do corpus}

As 2069 palavras tabu foram colocadas num ficheiro Excel para que os dados fossem prontamente acessíveis e analisáveis. As entradas são compostas pelas frases dos filmes em que as palavras tabu estão inseridas, para providenciar algum contexto à análise. Em seguida, classificámos, como uso marcado e não marcado, cada uma destas palavras tabu. Esta classificação foi efetuada tendo por base a proposta anterior relativa à adequação da linguagem tabu à situação comunicativa, ou seja, ao facto de as palavras tabu utilizadas pelos falantes serem, ou não, expectáveis de acordo com o contexto situacional, pela combinação das três variáveis do registro.

\subsection{Resultados e discussão}

Em seção anterior, associámos o uso não marcado da linguagem tabu à adequação da linguagem tabu em contextos situacionais informais em que os falantes têm uma relação próxima, ou, por outro lado, o uso marcado da linguagem tabu a contextos formais, cujos falantes têm relações distantes. Nestes termos, identificámos os padrões linguísticos de uso marcado e não marcado da linguagem tabu nos textos audiovisuais ficcionais em estudo, através da classificação e quantificação de ambas as categorias no corpus.

Considerando isto, o quadro representa as frequências absoluta e relativa das palavras tabu do corpus classificadas como uso marcado e uso não marcado, de acordo com a sua adequação ao contexto. 
QUADRO 8 - Distribuição absoluta e relativa das palavras tabu de uso marcado e não marcado

\begin{tabular}{|c|c|c|}
\hline Uso & Frequência absoluta & Frequência relativa \\
\hline Uso marcado & 179 & $9 \%$ \\
\hline Uso não marcado & 1890 & $91 \%$ \\
\hline
\end{tabular}

A leitura do quadro ilustra a distribuição não equitativa do uso marcado e não marcado da linguagem tabu, justificada pelo predomínio do uso não marcado das palavras tabu. Desta forma, foi possível concluir que, na maioria das situações comunicativas ficcionais dos filmes, a linguagem tabu é utilizada em situações informais e orais, nas quais os participantes têm uma relação próxima, decorrente de contato frequente, envolvimento afetivo elevado e poder igual ou semelhante.

Em mais detalhe, os exemplos seguintes, retirados do corpus, ilustram situações de uso marcado e não marcado da linguagem tabu:

Capitão Queenan - Congratulations on passing the detective's exam, and welcome to the Special Investigation Unit.

Sargento Dignam - Whoop-de-fucking-doo.

Capitão Queenan - You are a worker. You rise fast.

Sargento Dignam - Like a 12-year-old's dick.

$[\ldots]$

Capitão Queenan - Do you know what we do here? My section?

Billy - No idea. Zip. None.

Capitão Queenan - If you had an idea what we do, we would not be good at what we do, would we?

Sargento Dignam - We would be cunts. Are you calling us cunts?

Nas primeiras cenas de The Departed, uma das principais personagens, Billy Costigan, está reunido com o Sargento Dignam e com o Capitão Queenan após passar no exame para detective da Unidade de Investigação Especial da Polícia de Boston. É a primeira vez que se veem e o objetivo da reunião é levar Billy a aceitar uma posição de agente infiltrado no submundo do crime de Boston. Dignam recorre frequentemente a palavras tabu para provocar Billy, com o intuito de perceber se ele tem alguma dupla 
intenção ao entrar no departamento já que é proveniente, por parte do pai, de famílias desfavorecidas, com historial de crimes como tráfico de droga e assassinatos. O recurso à linguagem tabu pelo Sargento foi classificado como uso marcado uma vez que remete para o uso surpreendente da linguagem tabu numa situação comunicativa formal e profissional, na qual os participantes ficcionais têm uma relação distante, determinada pelo poder diferente, o contato nulo e o baixo envolvimento afetivo, não se esperando, naturalmente, o uso de uma das palavras mais ofensivas da linguagem tabu em língua inglesa (cunt) por parte de um polícia.

Por outro lado, o recurso à palavra tabu não é inadequado em situações comunicativas como a que ilustramos abaixo porque está dependente de um contexto de informalidade e de oralidade, cujos participantes ficcionais têm uma relação próxima, resultante das relações de poder, contato e envolvimento afetivo. Em Goodfellas, uma das personagens, Tommy, facilmente identificado como marginal pela agressividade com que lida com situações comuns do dia a dia, conta aos amigos como agrediu outra pessoa. Tommy utiliza geralmente palavras tabu de forma enfática, neste caso a palavra "fucking" repetida, para tornar a sua descrição mais emocionante, sendo esta a forma de falar típica do grupo em que Tommy está inserido. Todas estas personagens têm igual poder e utilizam frequentemente estas palavras tabu como forma de se identificarem e de se reconhecerem como pares.

Tommy - What are you going to do? What?

I fucking fly at him.

I got him and I'm banging his head, banging his fucking face.

I'm pulling his hair out of his head.

I beat him to a pulp. To a fucking pulp I beat him.

He's laying there full of fucking blood.

I'm out of breath.

\section{Considerações finais}

Neste estudo exploratório, recuperámos a proposta da Linguística Sistémico-Funcional e a teoria da adequação da linguagem ao contexto, para aplicar os conceitos de uso marcado e não marcado à análise do uso da linguagem tabu. Chegámos a diferentes conclusões, quer do ponto de vista teórico, quer aplicado. 
Concluímos que, tendencialmente, o uso não marcado da linguagem tabu estaria relacionado com os contextos oral informal ou escrito informal, nos quais os falantes ficcionais tinham relações próximas ou íntimas, ou seja, de igual poder, contato frequente e envolvimento afetivo elevado, que utilizam opções linguísticas típicas da linguagem comum. Por outro lado, propusemos que o uso marcado do tabu relacionar-se-ia com os contextos escrito formal ou oral formal, com uso de linguagem técnica ou especializada, entre personagens com relação distante, i.e. com poder tendencialmente hierárquico, contato pouco frequente e envolvimento fraco. Focamos a aplicabilidade da proposta, podendo esta ser tornada aplicável em diferentes contextos do uso da linguagem, quer autênticos quer ficcionais. No caso específico deste estudo exploratório, concluímos que a grande maioria das palavras tabu é usada de forma não marcada. Contudo, e apesar da função mimética característica da ficção audiovisual, acreditamos que a mesma proposta aplicada a um corpus de linguagem natural, autêntica, possa ter diferentes resultados. Disto, se depreende a necessidade de mais estudos focados no tema.

Ainda que seguindo a orientação de um estudo exploratório, vemos como limitação deste estudo a representatividade do corpus. Acreditando, ainda assim, que a dimensão deste corpus é adequada para um único pesquisador, consideramos que um corpus mais extenso possa atingir generalizações mais abrangentes e talvez diferentes.

\section{Referências}

AKMAJIAN, A.; DEMERS, R.; FARMER, A.; HARNISH, R. Linguistics: An Introduction to Language and Communication. Cambridge; London: The MIT Press, 2001.

ALLAN, K.; BURRIDGE, K. Forbidden Words. Taboo and the Censoring of Language. Cambridge: Cambridge University Press, 2006. DOI: https://doi. org/10.1017/CBO9780511617881

ALLAN, K.; BURRIDGE, K. Swearing. In: PETERS, P.; COLLINS, P.; SMITH, A. (ed.). Comparative Studies in Australian and New Zealand English. Grammar and Beyond. Amsterdam; Philadelphia: John Benjamins, 2009. p. 359-384. DOI: https://doi. org/10.1075/veaw.g39.20all

ANDERSSON, L.; TRUDGILL, P. Bad Language. Oxford: Blackwell, 1990. 
ANTHES, E. Profane Brain. Psychology Today, [S.l.] v. 43: 4, n. 22, 2010. Disponível em: https://www.psychologytoday.com/us/articles/201007/language-profanebrain. Acesso em: $1^{\circ}$ abr. 2018.

BEDNAREK, M. The Multifunctionality of Swear/Taboo Words in Television Series. In: MACKENZIE, J. L.; ALBA-JUEZ, L. (ed.). Emotion in Discourse. Amsterdam: John Benjamins, 2019. p. 29-54. DOI: https://doi.org/10.1075/ pbns.302.02bed

BEERS FÄGERSTEN, K. Who's Swearing Now? The Social Aspects of Conversational Swearing. Newcastle: Cambridge Scholars Publishing, 2012.

BEERS FÄGERSTEN, K.; STAPLETON, K. Advances in Swearing Researcb: New Languages and New Contexts. Amsterdam: John Benjamins, 2017. DOI: https:// doi.org/10.1075/pbns.282

BROCA, P. P. Sur la faculté générale du langage, dans ses rapports avec la faculté du langage articule. Bulletin de la Société d'Anthropologie, Paris, v. 1, p. 377-382, 1865. DOI: https://doi.org/10.3406/bmsap.1865.9495

COLLINS, P.; HOLLO, C. English Grammar: An Introduction. London: Macmillan, 2000.

CRESSMAN, D. L.; CALLISTER, M.; ROBINSON, T.; NEAR, C. Swearing in the Cinema. An Analysis of Profanity in US Teen-Oriented Movies, 1980-2006. Journal of Children and Media, [S.l.] v. 3, n. 2, p. 117-135, 2009. DOI: https://doi. org/10.1080/17482790902772257.

EGGINS, S. An Introduction to Systemic Functional Linguistic. London: Pinter, [1994] 2004.

FIRTH, J. Papers in Linguistics: 1934-1951. Oxford: Oxford University Press, 1951.

GODDARD, C. Swear Words' and 'Curse Words' in Australian (and American) English. At the Crossroads of Pragmatics, Semantics and Sociolinguistics. Intercultural Pragmatics, [S.l.], v. 12, n. 2, p. 189-218, 2015. DOI: https://doi. org/10.1515/ip-2015-0010

GOUVEIA, C. Texto e Gramática: uma introdução à Linguística SistémicoFuncional. Matraga, Rio de Janeiro, v. 16, n. 24, 2009. p. 13-47. Disponível em: http:/ / www.e-publicacoes.uerj.br/index.php/matraga/article/view/27795/19916. Acesso em: $1^{\circ}$ abr. 2018.

HALLIDAY, M. A. K. Explorations in the Functions of Language. London: Edward Arnold, 1973. 
HALLIDAY, M. A. K. Learning How to Mean. London: Edward Arnold, 1975. DOI: https://doi.org/10.1016/B978-0-12-443701-2.50025-1

HALLIDAY, M. A. K. Language as Social Semiotic: The Social Interpretation of Language and Meaning. London: Edward Arnold, 1978.

HALLIDAY, M. A. K. Introduction to Functional Grammar. 4. ed. Revised by Christian M. I. M. Matthiessen. London; New York: Routledge, [1985] 2014. DOI: https:// doi.org/10.4324/9780203431269

HALLIDAY, M. A. K.; MCINTOSH, A.; STREVENS, P. The Linguistic Sciences and language Teaching. London: Longman, 1964.

HALLIDAY, M. A. K.; HASAN, R. Language, Context, and Text: Aspects of Language in a Social-Semiotic Perspective. 2. ed. Oxford: Oxford University Press, [1985] 1989.

HYMES, D. Foundations in Sociolinguistics. An Ethnographic Approach. New Jersey: University of Pennsylvania Press, 1974.

JACKSON, J. H. On the Nature of the Duality of the Brain. 1874. In: TAYLOR, J. (ed.). Selected Writings of John Hughlings Jackson. London: Hodder \& Stoughton, 1958. v. 2, p. 129-145.

JAY, T. Why We Curse: A Neuro-Psycho-Social Theory of Speech. Amsterdam; Philadelphia: John Benjamins, 2000. DOI: https://doi.org/10.1075/z.91

JOSEPH, J. E. Language and Politics. Edinburgh: Edinburgh University Press, 2006. KARJALAINEN, M. Where Have All the Swearwords Gone? An Analysis of the Loss of Swearwords in two Swedish Translations of J. D. Salinger's Catcher in the Rye. 2002. Dissertação (Mestrado) - Faculty of Arts, Department of English, University of Sweden, 2002.

LABOV, W. The Social Stratification of English in New York City. New York: Cambridge University Press, 1966.

LABOV, W. Sociolinguistic Patterns. Philadelphia: University of Pennsylvania Press, 1972.

LABOV, W. Principles of Linguistic Change. v. 2: Social Factors. Massachusetts: Blackwell Publishers, 2001.

LANCKER, D. V.; CUMMINGS, J. L. Expletives: Neurolinguitic and Neurobehavioral Perspectives on Swearing. Brain Research Reviews, [S.l.], v. 31, p. 83-104, 1999. DOI: https://doi.org/10.1016/S0165-0173(99)00060-0

LJUNG, M. Swearing: A Cross-Cultural Linguistic Study. UK: Palgrave Macmillan, 2011. DOI: https://doi.org/10.1057/9780230292376 
MALINOWSKI, B. K. Coral Gardens and Their Magic. London: Allen \& Unwin, 1935. MARTIN, J.R. Language, Register and Genre. In: CHRISTIE, F. (ed.). Children Writing: A Reader. Geelong: Deakin University Press, 1984. p. 21-29.

MCENERY, A.; XIAO, Z. Swearing in Modern British English: The Case of Fuck in the NBC. Language and Literature, [S.l.], v. 13, p. 235-268, 2004. DOI: https:// doi.org/10.1177/0963947004044873

MCENERY, T. Swearing in English. Bad Language, Purity and Power from 1585 to the Present. London; New York: Routledge, 2006.

MILROY, J.; MILROY, L. Authority in Language, Investigating Language Prescription and Standardization. London: Routledge, [1985] 2012. DOI: https://doi. org/10.4324/9780203124666

MONTAGU, A. The Anatomy of Swearing. New York: Macmillan, 1967.

OLIVEIRA, S. M. Identidade pessoal e a relevância da análise de "frames" (molduras) para um modelo da negociação de tratamento. In: CONGRESO DE ROMANISTAS ESCANDINAVOS, XVI., 2006, Roskilde. Proceedings [...]. Roskilde, Denmark: Department of Language and Culture, Roskilde University, 2006. Disponível em: http:/ / www.ruc.dk/cuid/publikationer/publikationer/XVISRK-Pub/SMO/SMO03-Oliveira. Acesso em: $1^{\circ}$ abr. 2018.

POYNTON, C. Language and Gender: Making the Difference. Geelong: Deakin University Press, 1985.

RYAN, E. B. Why do Low-Prestige Language Varieties Persist? In: GILES, H.; ST. CLAIR, R. (ed.). Language and Social Psychology. Oxford: Basil Blackwell, 1979. p. $145-157$.

SOLER PRADO, B. Swearing and Translation: A Study of the Insults in the Films of Quentin Tarantino. 2011. Tese (Doutorado) - Universitat de Valencia, Valencia, 2011.

STAPLETON, K. Swearing. Interpersonal Pragmatics, [S.l.], v. 6, p. 289-306, 2010.

TAGG, C. A Corpus Linguistics Study of Text Messaging. 2009. Tese (Doutorado) University of Birmingham, Birmingham, 2009. 


\section{ANEXO I. Amostra do ficheiro Excel que compõe o corpus}

\begin{tabular}{|c|c|c|}
\hline Palavra tabu + contexto & Classificação & Uso \\
\hline I'm through doing that shit. & Tabu & marcado \\
\hline a sensible fucking man. & Tabu & não marcado \\
\hline Why should they give a fuck? & Tabu & não marcado \\
\hline Fucking way, it works & Tabu & não marcado \\
\hline a fucking phone. & Tabu & não marcado \\
\hline a fucking finger. & Tabu & não marcado \\
\hline even speak fucking English. & Tabu & não marcado \\
\hline they don't know what the fuck & Tabu & não marcado \\
\hline fucker's gonna make us kill him & Tabu & não marcado \\
\hline it's these old fucking Jews... & Tabu & não marcado \\
\hline for fifteen fucking generations. & Tabu & não marcado \\
\hline with a fucking Magnum & Tabu & não marcado \\
\hline Fuck it. We're out of it. & Tabu & não marcado \\
\hline he don't give a fuck. & Tabu & não marcado \\
\hline Fucking forget it. & Tabu & não marcado \\
\hline really give a fuck & Tabu & não marcado \\
\hline fucking pricks move... & Tabu & não marcado \\
\hline fucking pricks move... & Tabu & não marcado \\
\hline motherfucking last one of you! & Tabu & não marcado \\
\hline I'm fucking going. & Tabu & não marcado \\
\hline they got the same shit & Tabu & não marcado \\
\hline what the fuck a quarter pounder is & Tabu & não marcado \\
\hline Goddamn! & Tabu & não marcado \\
\hline They fucking drown 'em & Tabu & não marcado \\
\hline in that shit. & Tabu & não marcado \\
\hline We should have fucking shotguns. & Tabu & não marcado \\
\hline Marsellus fucked him up good. & Tabu & não marcado \\
\hline So, what'd he do, fuck her? & Tabu & não marcado \\
\hline
\end{tabular}

Data de submissão: 24/01/2020. Data de aprovação: 02/11/2020. 